\section{Kastamonu Eğitim Dergisi Kastamonu Education Journal}

Kasım 2019 Cilt:27 Sayı:6

kefdergi.kastamonu.edu.tr
Başvuru Tarihi/Received: 25.01.2019

Kabul Tarihi/Accepted: 28.03.2019

DOI: $10.24106 /$ kefdergi.3554

\title{
Sosyal Çevre ve Öğrenme Ortamı Ölçeği’nin Türkçeye Uyarlanması: Geçerlik ve Güvenirlik Çalışması ${ }^{1}$
}

\section{Adaptation of the Social Context and Learning Environment Scale to Turkish: Validity and Reliability Study}

\section{Öz}

\author{
Hatice ALTUNKAYA2 ${ }^{2}$ Ahmet BAŞKAN ${ }^{3}$
}

Bu çalışmanın amacı, Sosyal Çevre ve Öğrenme Ortamı Ölçeği'nin Türkçeye uyarlanması ve psikometrik özelliklerinin tespit edilmesidir. Araştırma 2017-2018 eğitim-öğretim yılında Dicle Üniversitesi Ziya Gökalp Eğitim Fakültesinin farklı bölümlerinde öğrenim gören 310 öğretmen adayı ile gerçekleştirilmiştir. Sosyal Çevre ve Öğrenme Ortamı Ölçeği'nin geçerliğini ve güvenirliğini ortaya koymak için doğrulayıcı ve açıklayıcı faktör analizleri yapılmıştır. Analizler neticesinde, ölçeğin güvenirliğini ifade eden Cronbach's Alpha değeri 0,931 olarak yüksek bulunmuştur. İç tutarlılı̆ı olumsuz etkileyen ve madde toplam korelasyon değeri 0,17 olan 14 numaralı "Bazen öğretmenim ve kendimi sınıfta zıt grupmuşuz gibi hissediyorum" maddesi ölçekten çıkartılmış ve sonuçta 26 madde, 4 boyuttan oluşan bir ölçek ortaya konmuştur. Ölçeğin (1-10. maddeler) birinci alt boyutu genel öğrenci-öğrenci ilişkileri için 0,887; ikinci alt boyutu (11-15. maddeler[14. madde çıkarıldı]) resmî öğretmen-öğrenci ilişkileri için 0,777; üçüncü alt boyutu (16-20. maddeler) resmî olmayan öğretmen-öğrenci ilişkileri için 0,830; dördüncü alt boyutu (21-27. maddeler) eğitmen olarak öğrenci faktörü için ise 0,867 Cronbach's Alpha değeri tespit edilmiştir. Ölçek, toplam varyansın \%56.489'ünü açıklamaktadır. 26 madde, 4 alt boyuttan oluşan Sosyal Çevre ve Öğrenme Ortamı Ölçeği'nin geçerli ve güvenilir bir ölçme aracı olarak öğrenme ortamlarında kullanılabileceği söylenebilir.

Anahtar Kelimeler: Sosyal çevre, öğrenme ortamı, ölçek.

\section{Abstract}

The aim of this study is to determine the adaptation and psychometric properties of the Social Context and Learning Environment Scale to Turkish. The research was carried out with 310 prospective teachers in different departments of Dicle University Ziya Gökalp Faculty of Education in the academic year of 2017-2018. Confirmatory and explanatory factor analyzes were conducted to establish the validity and reliability of the Social Context and Learning Environment Scale. As a result of the analyzes, the reliability of the scale was found high as Cronbach's Alpha $=0,931$. The item 14, which has a negative effect on internal consistency and whose item total correlation value is 0,17 was removed from the scale and a scale consisting of 26 items and 4 dimensions was determined. The first subscale of the scale (items 1-10) was 0.887 for general student-student relationships; the second sub-dimension (items $11-15$ [item 14 extracted]) is 0.777 for the official teacher-student relationships; the third sub-dimension (16-20 items) for non-official teacher-student relationships is 0.830; the fourth sub-dimension (items 21-27) was found to be 0.867 Cronbach's Alpha value for the student factor as an instructor. The scale explains $56.489 \%$ of the total variance. It can be said that the Social Context and Learning Environment Scale consisting of 26 items and 4 subscales can be used in learning environments as a valid and reliable measurement tool.

Keywords: Social context, learning environment, scale.

1. Bu çalışma 13-15 Eylül 2018 tarihleri arasında Aydın Adnan Menderes Üniversitesi'nde düzenlenen II. Uluslararası Eğitim Araştırmaları ve Öğretmen Eğitimi Kongresi'nde sözlü bildiri olarak sunulmuştur.

2. Aydın Adnan Menderes Üniversitesi, Eğitim Fakültesi Türkçe Eğitimi Ana Bilim Dalı, Aydın, Türkiye; http://orcid.org/0000-0003-4498-194X

3. Dicle Üniversitesi, Ziya Gökalp Eğitim Fakültesi Türkçe Eğitimi Ana Bilim Dalı, Diyarbakır, Türkiye; https://orcid.org/0000-0003-4028-9067

Atıf / Citation: Altunkaya, H. ve Başkan, A. (2019). Sosyal Çevre ve Öğrenme Ortamı Ölçeği'nin Türkçeye uyarlanması: Geçerlik ve güvenirlik çalışması. Kastamonu Education Journal, 27(6), 2671-2679. doi:10.24106/kefdergi.3554 


\section{Extended Abstract}

Introduction: At the present time, modern educational approach has adopted a constructivist approach to education. It is understood that this theory emphasizes the social environment, culture and cooperative dimension (Terwel, 1999). According to Vygotsky (1978), learning of the individual requires a special social environment. Language and thought are seen as two main factors in this social process which is necessary for the learning and development of the individual (Vygotsky, 1978, 1986). According to the social constructivism theory, learning takes place with the help of social activities. The structuring of the meaning and structuring of knowledge takes place during the discussion and reflection process with the group members and the instructor (Higgs and McCarthy, 2005). The importance of social interaction is frequently emphasized in the completion of the learning process (Garrison, 2000; Tu and Corry, 2002). Access to the targeted gains in education can be possible with the warm relationships between the students and their teachers. In the classroom learning environment, as well as the relationship of the students with each other, the relationship between the teacher and the classroom is one of the important factors for learning success.

Walker and Baepler (2017) stated that the social environment in the classroom environment consists of a network of relationships with students and students, and the need to conceptualize and measure how effective the relationships in this environment are in the education process. Walker and Baepler (2017) stated that this measure is important when the classroom space is thought to affect learning and that social interaction is crucial and that a class with more student participation may affect learning performance as opposed to a traditional class that does not prioritize social relationships. From this point of view, researchers have developed the Social Context and Learning Environment Scale in order to measure social relations in the new class areas.

Method: The study was carried out by using the scanning model. The scanning models describe a situation that has existed in the past or is still present (Karasar, 2009: 77). The study was carried out with the participation of the students studying at Dicle University Ziya Gökalp Faculty of Education in the spring term of 2017-2018 academic year. In the study, Social Context and Learning Environment Scale developed by Walker and Baepler (2017) was used as a data collection tool. Social Context and Learning Environment Scale is a 26-item scale supporting 4 factor structure.

Findings, Results and Recommendations: In this study, adaptation, validity and reliability of Social Context and Learning Environment Scale developed by Walker and Beapler (2017) were examined. In the translation stage, the scale was translated into Turkish according to expert opinions and applications were carried out with 310 prospective teachers from different departments. As a result of the analyzes, the reliability of the scale was found high as Cronbach's Alpha = 0,931. The item 14 (Sometimes I feel like my instructor and I are on opposing teams in this class), which has a negative effect on internal consistency and whose item total correlation value is 0,17 was removed from the scale and a scale consisting of 26 items and 4 dimensions was determined. The first sub-dimension of the scale (items 1-10) is 0.887 for general student-student relations; second sub-dimension (items $11-15$ [item 14 removed]); 0,777 for formal teacher-student relations; the third sub-dimension (items 16-20) for the non-formal teacher-student relationship 0,830; The fourth sub-dimension (items 21-27) and the 0,867 Cronbach's Alpha values were determined for the student factor..

The total variance of the scale was $56.489 \%$. Considering that the rate of variance explained in scale development and adaptation studies is taken as $30 \%$ or more, it is seen that the construct validity of the scale is ensured (Ural \& Kılıç, 2006). It can be said that Social Context and Learning Environment Scale consisting of 26 items and 4 sub-dimensions can be used as a valid and reliable measurement tool in learning environments. Scale adaptation studies were carried out with the students of the faculty of education. In different studies conducted by the researchers, validity and reliability studies of the scale can be done in different age and sample groups. It is also thought that the scale can be used to determine the relationship between different skill areas and learning environment. 


\section{Giriş}

Günümüzde çağdaş eğitim anlayışı, yapılandırmacı eğitim yaklaşımını benimsemiştir. "Bu kuramın öğrenmenin sosyal çevre, kültür ve işbirlikli boyutunu vurguladığı bilinmektedir (Terwell, 1999). Vygotsky'ye göre (1978) bireyin öğrenmesi, özel bir sosyal çevreyi gerektirmektedir. Bireyin öğrenmesinde ve yetişmesinde gerekli olan bu sosyal süreçte dil ve düşünce iki temel faktör olarak görülmektedir (Vygotsky, 1978, 1986). Sosyal yapılandırmacılık kuramına göre, öğrenme birlikte yapılan sosyal etkinlikler yardımıyla gerçekleşir. Anlamın şekillenmesi ve bilginin yapılanması grup üyeleri ve öğretim elemanı ile olan tartışma ve yansıma sürecinde gerçekleşir (Higgs ve McCarthy, 2005). Yapılan araştırmalarda öğrenme sürecinin tamamlanmasında, sosyal etkileşimin önemi sıkça vurgulanmaktadır (Garrison, 2000; Tu ve Corry, 2002). Eğitimde hedeflenen kazanımlara erişmek, öğrencilerin birbirleri ile ve öğretmenleri ile kuracakları sıcak ilişkilerle mümkün olabilir. "Olumlu sınıf ortamının yaratılmasında ise sınıfta öğrenme çevresinin oluşturulması önem taşımaktadır. Sınıfta öğrenme çevresini kurallar ve beklentilerin açıklığı, ödül ve teşvikler, öğretmen yeteneği, yüksek beklenti, derse katılım, öğrenci-öğretmen ilişkileri, okul-aile ilişkileri, grup normları, öğretmen-öğretmen, öğretmen-yönetici ilişkileri, fiziksel çevre bileşenleri oluşturmaktadır" (Apaydın ve Kızılhan, 2011: 512).

Sınıf öğrenme çevresinin olumlu olmasının başarıyı artırmada bir faktör olduğuna dair çalışmalar (Kısakürek, 1985; Dorman, Fraser ve McRobbie, 1997; Kandemir, Çakır ve Eşici, 2009) literatürde bulunmaktadır. Sınıf öğrenme çevresinde öğrencilerin birbiri ile ilişkisi kadar öğretmenin sınıf ile ilişkisi de öğrenme başarısı için önemli olan faktörler arasındadır. "Sınıf atmosferinin olumluluğunda öğretmen-öğrenci ilişkilerinin önemli bir yeri vardır. Öğrenciye güven duyma, öğrenciye yakınlık gösterme, araya büyük mesafe koymama, öğrencilerin karşılaştkkları sorunları ve yaşadıkları problemleri anlayışla karşılama; öğrenci başarısını olumlu yönde etkileyen güdüleme unsurları olarak görülmektedir. Öğrencilerin derste uyulması gereken kuralları önceden bilmesi, öğretim üyesinin bunlara önem vermesi ile öğretim üyesinin bu konularda hoşgörülü olması bir dereceye kadar başarıyı etkileyen faktörler olarak ortaya çıkmaktadır" (Telli ve Çakıroğlu, 2002; Aldridge, Dorman ve Fraser; 2004; Küçükoğlu ve Köse; 2008'den akt. Köse ve Küçükoğlu, 2009).

Köse ve Küçükoğlu (2009) çeşitli üniversitelerin eğitim fakültelerinde öğrenim görmekte olan öğretmen adaylarının dâhil oldukları sınıf öğrenme çevresinden nasıl etkilendiklerini araştırmış ve cinsiyet, ana bilim dalı ve sınıf düzeyi değişkenlerine göre öğrenci görüşleri arasında, başarılarını etkileme yönünde anlamlı farklııklar bulunmasının yanında, genel olarak öğrenci başarılarında sınıf öğrenme çevresinin önemli bir etken olduğunu tespit etmişlerdir. Öğrenme çevrelerinin etkisini belirlemeye çalışan çeşitli ölçme aracı geliştirme çalışmalarının (Walberg ve Anderson, 1968; Moos, 1979; Rentoul ve Fraser, 1979; Fisher ve Fraser, 1981; Taylor, Fraser ve White, 1994; Taylor, Fraser ve Fisher, 1997) ilgili literatürde bulunduğu görülmektedir. Küçüközer, Kırtak Ad, Ayverdi ve Eğdir (2012); Taylor, Fraser ve Fisher (1997) tarafindan geliştirilen Yapılandırmacı Öğrenme Ortamı Ölçeği'ni Türkçe'ye uyarlamış ve ölçeğin geçerlik ve güvenirliğini incelemişlerdir.

Sınıftaki sosyal çevrenin ve öğrenme ortamının ölçülmesine yönelik bir çalışmanın da Walker ve Baepler (2017) tarafindan yapıldığı görülmektedir. Walker ve Baepler (2017) sınıf ortamında sosyal çevrenin, öğrencilerin öğrencilerle ve eğitmenlerin öğrencilerle kurduğu ilişkiler ağından oluştuğunu ve bu çevredeki ilişkilerin eğitim sürecinde ne kadar etkili olduğunun kavramsallaştırılması ve ölçülmesi gerektiğini ifade etmişlerdir. Walker ve Baepler (2017) bu ölçmenin, sınıf alanının öğrenmeyi nasıl etkilediği düşünüldüğünde önemli olduğunu, sosyal etkileşimi iyi, öğrenci katlımı daha fazla olan bir sınıfin sosyal ilişkileri ön planda tutmayan geleneksel bir sınıftan farklı olarak öğrenme performansını etkileyebileceğini ifade etmişlerdir. Bu durumdan hareketle araştırmacılar yeni sınıf alanlarında sosyal ilişkileri ölçmek amacıyla Sosyal Çevre ve Öğrenme Ortamı Ölçeği (Social Context and Learning Environments Scale) geliştirmişlerdir. Walker ve Baepler (2017) ölçeğin eğitmenler tarafindan farklı öğrenme alanlarındaki sosyal çevredeki ilişkileri ölçmede ve öğrencilerin öğrenme sonuçlarını iyileştirmeye yönelik çabaları yönlendirmede kullanılabileceğini ifade etmişlerdir. Gelişen eğitim bilimleri, öğrenme-öğretme yöntemleri, eğitim teknolojileri ile eğitim süreçlerinde geleneksel sınıfların aksine yeni sosyal çevre ilişkilerini içeren öğrenme ortamları gündeme gelmektedir. Değişen öğrenme ortamlarında yeni sınıfların öğrenme ve öğretmeyi nasıl ve hangi yolla etkilediği sorusundan yola çıkılarak geliştirildiği ifade edilen çalışmada amacın, öğrenme alanlarının öğretme-öğrenme sürecini nasıl şekillendirdiğini kavramsallaştırarak ve özellikle öğrenmenin sosyal yönündeki değişimlere odaklanarak bu soruya cevap verebilmek olduğu ifade edilmiştir. Ölçeğin Türkçeye uyarlaması ile değişen sınıf ortamlarının bileşenlerini doğru bir şekilde ölçebilmek ve ortaya çıkan bileşenler doğrultusunda eğitmenlere yol gösterici bir araç ortaya koyabilmek hedeflenmektedir. Öğrenmede önemli olan dil, düşünce, sosyal çevre ve bunların bulunduğu öğrenme ortamının nasıl olduğunun, öğrenenlerin nasıl öğrendiğinin ve bu sosyal çevrenin öğrenciler üzerinde nasıl bir etkisinin bulunduğu ve öğreticilerin bu çevre ve ortamlarda nasıl etkilendiğinin tespit edilmesinin daha başarılı eğitim ortamlarının düzenlenebilmesi açısından yararlı olacağı düşünülmektedir. Bu bağlamda, bu araştırmanın amacı, Sosyal Çevre ve Öğrenme Ortamı Ölçeği'nin (Walker ve Baepler, 2017) Türkçeye uyarlanması, geçerlik ve güvenirlik çalışmalarının gerçekleştirilmesidir. 


\section{Yöntem}

Çalışma, tarama modeli kullanılarak gerçekleştirilmiştir. "Tarama modellerinde geçmişte ya da halen var olan bir durum betimlenir. Araştırmaya konu olan birey ya da nesne kendi koşulları içerisinde olduğu gibi tanımlanmaya çalışılır" (Karasar, 2009: 77).

\section{Çalışma Grubu}

Çalışma, 2017-2018 eğitim öğretim yılı bahar döneminde Dicle Üniversitesi Ziya Gökalp Eğitim Fakültesi'nde öğrenim gören öğrencilerin katlımı ile gerçekleştirilmiştir. Çalışmada yer alan öğrencilere ait bilgiler aşağıda verilmiştir:

Tablo 1. Çalışma Grubuna İlişkin Tanımlayıcı Özellikler

\begin{tabular}{|c|c|c|c|}
\hline Tablolar & Gruplar & Frekans (n) & Yüzde (\%) \\
\hline \multirow{3}{*}{ 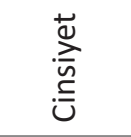 } & Kadın & 201 & 64,8 \\
\hline & Erkek & 109 & 35,2 \\
\hline & Toplam & 310 & 100,0 \\
\hline \multirow{5}{*}{$\stackrel{4}{\stackrel{\leftrightarrows}{\leftrightarrows}}$} & 1 & 50 & 16,1 \\
\hline & 2 & 66 & 21,3 \\
\hline & 3 & 80 & 25,8 \\
\hline & 4 & 114 & 36,8 \\
\hline & Toplam & 310 & 100,0 \\
\hline \multirow{6}{*}{$\frac{\varepsilon}{: \supset}$} & Türkçe Öğretmenliği & 138 & 44,5 \\
\hline & Sınıf Öğretmenliği & 88 & 28,4 \\
\hline & Türk Dili ve Ed. Öğretmenliği & 38 & 12,3 \\
\hline & Okul Öncesi Öğretmenliği & 24 & 7,7 \\
\hline & Coğrafya Öğretmenliği & 22 & 7,1 \\
\hline & Toplam & 310 & 100,0 \\
\hline
\end{tabular}

Tablo 1'de görüldügü gibi çalışmaya katılan öğrenciler, cinsiyete göre $201^{\prime} i(\% 64,8)$ kadın, $109^{\prime}$ u $(\% 35,2)$ erkek olarak dağılmaktadır. Sınıfa göre incelendiğinde katılımcıların 50'sinin $(\% 16,1)$ birinci, 66'sının $(\% 21,3)$ ikinci, 80'inin $(\% 25,8)$ üçüncü, 114'ünün $(\% 36,8)$ dördüncü sınıfta oldukları görülmektedir. Bölüme göre dağılıma bakıldığında, araşttrmada ulaşılan öğrencilerin 138'inin (\%44,5) Türkçe Öğretmenliği, 88' inin (\%28,4) Sınıf Öğretmenliği, 38'inin (\%12,3) Türk Dili ve Edebiyat Öğretmenliği, 24 'ünün $(\% 7,7)$ Okul Öncesi Öğretmenliği ve 22 'sinin $(\% 7,1)$ Coğrafya Öğretmenliği lisans programında öğrenim gördükleri anlaşılmaktadır.

\section{Veri Toplama Araçları}

Walker ve Baepler (2017) tarafindan geliştirilen Sosyal Çevre ve Öğrenme Ortamı Ölçeği (Social Context and Learning Environments Scale), 26 maddeden oluşan 4 faktörlü bir yapıyı destekleyen bir ölçektir. Ölçeğin orijinali 1300 üniversite öğrencisi ile üç aşamalı bir süreçte geliştirilmiştir. Ölçeğin geliştirilme sürecinde 10. maddenin birden fazla faktöre göre nispeten düşük bir faktör yüklemesi ve çapraz yüke sahip olduğu için çıkarıldığı ifade edilmiştir. Uyarlama sürecinde bu madde de ölçekte bırakılmış ve analiz sonuçlarına tabi tutulmuştur. Kesinlikle Kathlıyorum (5), Kesinlikle Katılmıyorum (1) şeklinde 5'li Likert tipi bir derecelendirme kullanılmıştır.

\section{Ölçek Uyarlama İşlem Basamakları}

Yabancı dilden Türkçeye çevrilen ölçekleri uyarlama sürecinde atılması gereken başlıca iki adım vardır. Bunlar Yapı, kavram ve dil eşitliğini sağlanması ve ölçüm aracının psikometrik özelliklerini değerlendirilmesi şeklinde özetlenebilir (Şencan, 2005). Bu genel adımlar doğrultusunda ölçeği uyarlama işleminde aşağıdaki adımlar takip edilmiştir:

- Ölçeği uyarlama çalışmaları öncelikle Walker'dan ölçeğin uyarlanabilmesi için elektronik posta yolu ile izin alınması ile başlamıştır.

- Ölçek, araştrrmacılar tarafindan Türkçeye çevrilmiş ve sonrasında ölçek maddeleri üstte İngilizce aslı, altta çevirisi ve sağ taraftaki sütunlarda "uygun, uygun değil, öneriniz" şeklinde geri bildirim sütunları yer almıştır. Hazırlanan uzman görüş formunun üst kısmında yapılacak çalışmaya ilişkin bilgiler yer almış ve form, Türkçe ve İngilizce uzmanı 10 öğretim üyesinin görüşüne sunulmuştur. Öğretim üyelerinin yarısının kadın, yarısının erkek olmasına ve cinsiyetten kaynaklanan bir yansıma olmaması için dikkat edilmiştir.

- Uzmanlardan gelen öneriler doğrultusunda çeviriler, araştırmacılar tarafindan tekrar yapılandırılmıştır. Sonrasında Eğitim Bilimleri alanında uzman bir öğretim üyesi ve İngilizce öğretmenliği alanında bir uzman ile maddeler değerlendirilmiş, dil ve anlatım yönünden araştırmacılar tarafindan tekrar kontrolü sağlanarak ölçeğe 
son hâli verilmiş ve uygulama aşamasına geçilmiştir.

- Uygulama aşamasının ilk adımı, 35 öğrenci ile gerçekleştirilmiştir. Ölçekte yer alan maddelerin anlaşılır olup olmadığının ortaya konması için son hâli verilen ölçek maddeleri öğrencilere okunmuş, anlaşılmayan bir ifade olup olmadığı öğrencilere sorulmuştur. Öğrenciler ölçeğin anlaşılır olduğunu ifade etmişler, iki maddeye ilişkin öneri sunmuşlardır. Öğrencilerden gelen öneriler doğrultusunda ölçeğe son şekli verilmiştir.

- Ölçeğin uygulama aşaması gerçekleştirilmiş, veri seti hazırlanmıştır.

\section{Bulgular}

Bu araştrrmada Sosyal Çevre ve Öğrenme Ortamı Ölçeği'nin güvenirliği Cronbach's Alpha=0,931 olarak yüksek bulunmuştur. İç tutarlıığı olumsuz etkileyen ve madde toplam korelasyon değeri 0,17 olan 14 numaralı "Bazen öğretmenim ve kendimi sınıfta zıt grupmuşuz gibi hissediyorum" maddesi çıkartılmıştır.

\section{Doğrulayıcı Faktör Analizi}

Sosyal Çevre ve Öğrenme Ortamı Ölçeği, faktörlerinin yapı geçerliliğine ilişkin doğruluğunu belirlemek üzere farklı bir örneklem üzerinde toplanan veriler ile uyum sağlayıp sağlamadığını belirlemek üzere doğrulayıcı faktör analizi yapılmıştr. Çalışmada literatürde bulunan araştırmalarda en sık kullanılan uyum iyiliği indeksleri kullanıımıştr. Kullanılan uyum indekslerine dönük kabul edilen bazı referans değerler ve doğrulayıc faktör analizi sonrası uyum iyiliği kriterleri aşağıda verilmektedir.

Tablo 1. Uyum İyiliği İndeksleri ve Normal Değerleri

\begin{tabular}{lccc}
\hline Indeks & Normal Değer* & Kabul Edilebilir Değer* & Öğrenme Ortamı Ölçeği \\
\hline X2/sd değeri & $<2$ & $<5$ & 2.16 \\
GFI (Uyum İyiliği İndeksi) & $>0.95$ & $>0.90$ & 0.90 \\
AGFI & $>0.95$ & $>0.90$ & 0.90 \\
CFI (Karşılaşțrılmalı Uyum İndeksi) & $>0.95$ & $>0.90$ & 0.91 \\
RMSEA (Root Mean Square Error of Approximation) & $<0.05$ & $<0.08$ & 0.06 \\
RMR & $<0.05$ & $<0.08$ & 0.08
\end{tabular}

* Kaynaklar: (Şimşek, 2007; Hooper, Coughlan \& Mullen, 2008; Schumacker and Lomax, 2010; Waltz, Strcikland \& Lenz 2010; Wang \& Wang, 2012; Sümer, 2000; Tabachnick \& Fidel, 2007).

Analiz sonuçları, doğrulayıcı faktör analizi ile hesaplanan uyum istatistiklerinin modelin, katılımcılardan toplanan gerçek verilerle kabul edilebilir düzeyde uyumlu olduğunu göstermektedir. Bu durum ölçeğin daha önce belirlenen faktör yapısına göre iyi uyum gösterdiğine işaret etmektedir. Uyum iyiliği değerleri ile birlikte faktörler arasındaki korelasyon katsayısının 0,85'den küçük olması gerekmektedir. Faktörlerin birbirinden ayrı olduğuna ilişkin ayrım geçerliliği sağlanmaııdır. Ayrıca faktör yüklerinin yüksek, hata varyanslarının düşük, maddelerin faktör üzerinde oluşturduğu açıklayıcılık $\left(R^{2}\right)$ değerlerinin yüksek olması gereklidir (Kline, 2005; Çokluk, Şekercioğlu ve Büyüköztürk, 2010). Awang (2015) ayrıca faktör yüklemelerinin 0,50'den küçük olmamasını önermektedir. Doğrulayıc faktör analizine ilişkin diyagram aşağıda verilmiştir:

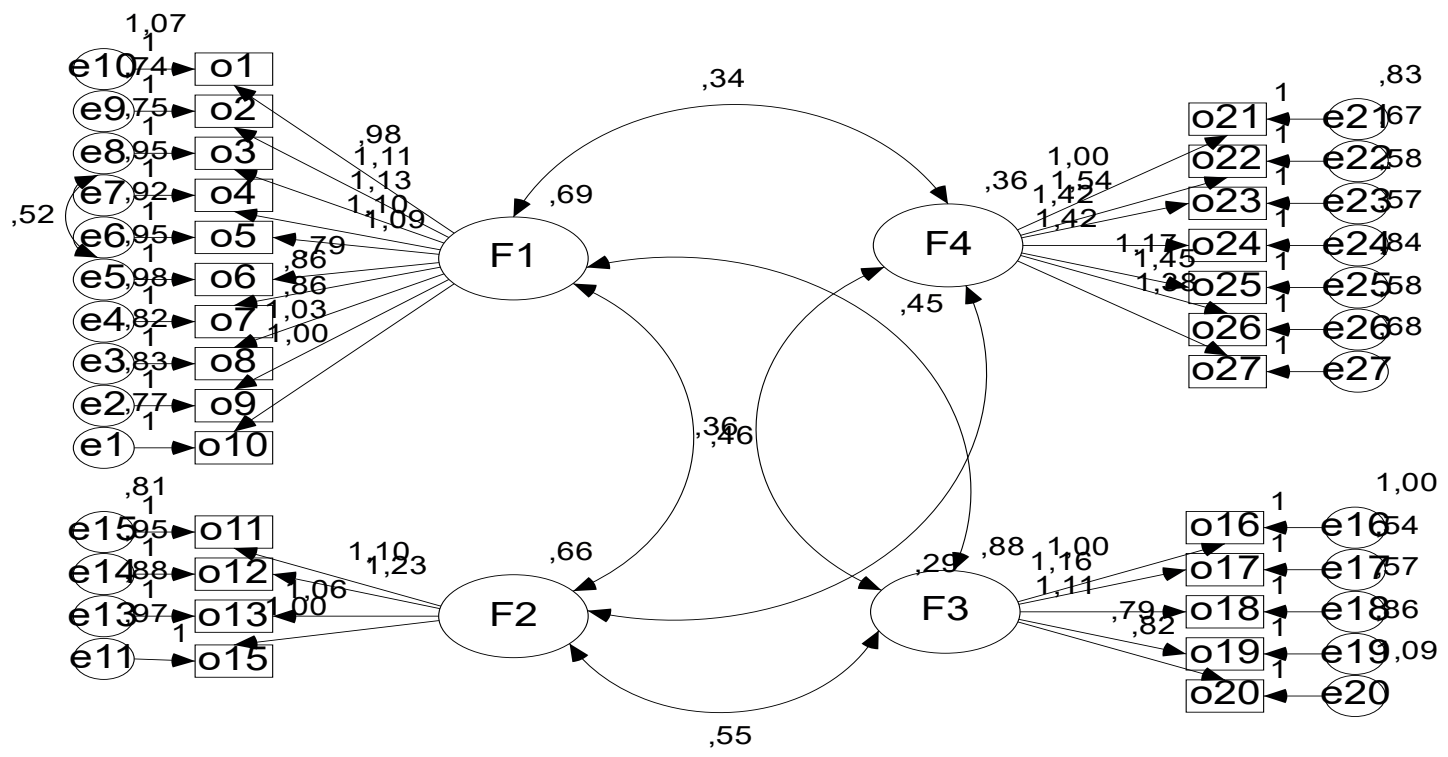

Şekil 1. Öğrenme Ortamı Ölçeği Doğrulayıcı Faktör Analizine illişkin Diyagram 
Faktörler arasındaki korelasyon katsayılarının 0,85'den küçük olması belirlenen faktörlerin birbirinden ayrı olduğunu göstermektedir. Ayrım geçerliliği sağlanmaktadır. Standardize edilmiş faktör yükleri, $t$ değerleri ve maddelerin oluşturduğu açıklayıcılık $\left(\boldsymbol{R}^{2}\right)$ değerleri aşağıda verilmektedir.

Tablo 2. Öğrenme Ortamı Ölçeği Faktör Yükleri ve Maddelere İlişkin Regresyon Katsayıları

\begin{tabular}{|c|c|c|c|c|c|c|c|c|}
\hline Maddeler & & Faktörler & $\beta$ & Std. $\beta$ & S.Hata & $\mathbf{t}$ & $p$ & $\mathbf{R}^{2}$ \\
\hline o10 & $<---$ & $\mathrm{F} 1$ & 1,000 & 0,688 & & & & 0,503 \\
\hline o9 & $<---$ & $\mathrm{F} 1$ & 1,026 & 0,683 & 0,094 & 10,924 & $p<0,001$ & 0,565 \\
\hline 08 & $<---$ & $\mathrm{F} 1$ & 0,862 & 0,620 & 0,086 & 9,978 & $p<0,001$ & 0,371 \\
\hline 07 & $<---$ & $\mathrm{F} 1$ & 0,860 & 0,585 & 0,091 & 9,459 & $p<0,001$ & 0,560 \\
\hline $\mathrm{O} 4$ & $<---$ & $\mathrm{F} 1$ & 0,793 & 0,559 & 0,087 & 9,064 & $p<0,001$ & 0,553 \\
\hline 05 & $<---$ & $\mathrm{F} 1$ & 1,090 & 0,687 & 0,099 & 10,964 & $p<0,001$ & 0,561 \\
\hline 06 & $<--$ & $\mathrm{F} 1$ & 1,099 & 0,684 & 0,101 & 10,920 & $p<0,001$ & 0,302 \\
\hline o3 & $<---$ & $\mathrm{F} 1$ & 1,125 & 0,733 & 0,097 & 11,646 & $p<0,001$ & 0,351 \\
\hline 02 & $<---$ & $\mathrm{F} 1$ & 1,107 & 0,730 & 0,095 & 11,606 & $p<0,001$ & 0,392 \\
\hline 01 & $<---$ & $\mathrm{F} 1$ & 0,975 & 0,616 & 0,098 & 9,924 & $p<0,001$ & 0,655 \\
\hline o15 & $<---$ & $\mathrm{F} 2$ & 1,000 & 0,637 & & & & 0,685 \\
\hline 013 & $<---$ & $\mathrm{F} 2$ & 1,058 & 0,674 & 0,112 & 9,454 & $p<0,001$ & 0,469 \\
\hline 012 & $<---$ & $\mathrm{F} 2$ & 1,225 & 0,715 & 0,124 & 9,849 & $p<0,001$ & 0,497 \\
\hline 011 & $<---$ & $\mathrm{F} 2$ & 1,102 & 0,705 & 0,113 & 9,761 & $p<0,001$ & 0,511 \\
\hline o16 & $<---$ & F3 & 1,000 & 0,685 & & & & 0,455 \\
\hline 017 & $<---$ & F3 & 1,158 & 0,828 & 0,092 & 12,600 & $p<0,001$ & 0,405 \\
\hline 018 & $<---$ & F3 & 1,106 & 0,809 & 0,089 & 12,387 & $p<0,001$ & 0,379 \\
\hline o19 & $<---$ & F3 & 0,794 & 0,626 & 0,080 & 9,910 & $p<0,001$ & 0,533 \\
\hline 020 & $<---$ & F3 & 0,818 & 0,593 & 0,087 & 9,416 & $p<0,001$ & 0,537 \\
\hline 021 & $<---$ & $\mathrm{F} 4$ & 1,000 & 0,549 & & & & 0,468 \\
\hline 022 & $<---$ & $\mathrm{F} 4$ & 1,540 & 0,749 & 0,165 & 9,332 & $p<0,001$ & 0,472 \\
\hline 023 & $<---$ & $\mathrm{F} 4$ & 1,417 & 0,743 & 0,153 & 9,293 & $p<0,001$ & 0,313 \\
\hline 024 & $<---$ & $\mathrm{F} 4$ & 1,423 & 0,748 & 0,153 & 9,326 & $p<0,001$ & 0,343 \\
\hline 025 & $<---$ & F4 & 1,170 & 0,609 & 0,142 & 8,226 & $p<0,001$ & 0,384 \\
\hline 026 & $<---$ & $\mathrm{F} 4$ & 1,452 & 0,752 & 0,155 & 9,351 & $p<0,001$ & 0,467 \\
\hline 027 & $<---$ & $\mathrm{F} 4$ & 1,382 & 0,709 & 0,153 & 9,046 & $p<0,001$ & 0,473 \\
\hline
\end{tabular}

Standardize edilmiş katsayılar incelendiğinde faktör yüklerinin yüksek, standart hata değerlerinin düşük, $\mathbf{t}$ değerlerinin anlamlı $(p<0,001), \boldsymbol{R}^{2}$ değerlerinin yüksek olduğu belirlenmiştir. Bu sonuçlar önceden belirlenen faktör yapısına ilişkin yapı geçerliliğini doğrulamaktadır.

\section{Açıklayıcı Faktör Analizi}

Ölçeğe ilişkin açıklayıcı faktör analizi sonucunda maddeler toplam açıklanan varyansı \%56.489 olan 4 faktör altında toplanmıştır. Ölçeğe ait oluşan açıklayıcı faktör yapısı aşağıda görülmektedir:

\section{Tablo 3. Öğrenme Ortamı Ölçeği Açıklayıcı Faktör Yapısı}

\begin{tabular}{lcccc}
\hline Boyut & Madde & Faktör Yükü & Açıklanan Varyans & Cronbach's Alpha \\
& O6 & 0,792 & \\
O5 & 0,765 & \\
O2 & 0,748 & \\
O3 & 0,657 & \\
F1: Genel öğrenci-öğrenci ilişkileri & O10 & 0,621 & \multirow{2}{*}{18,871} & 0,887 \\
(Öz değer=9.686) & O8 & 0,620 & \\
& O9 & 0,606 & \\
O1 & 0,541 & & \\
& O4 & 0,532 & & \\
& 07 & 0,509 &
\end{tabular}




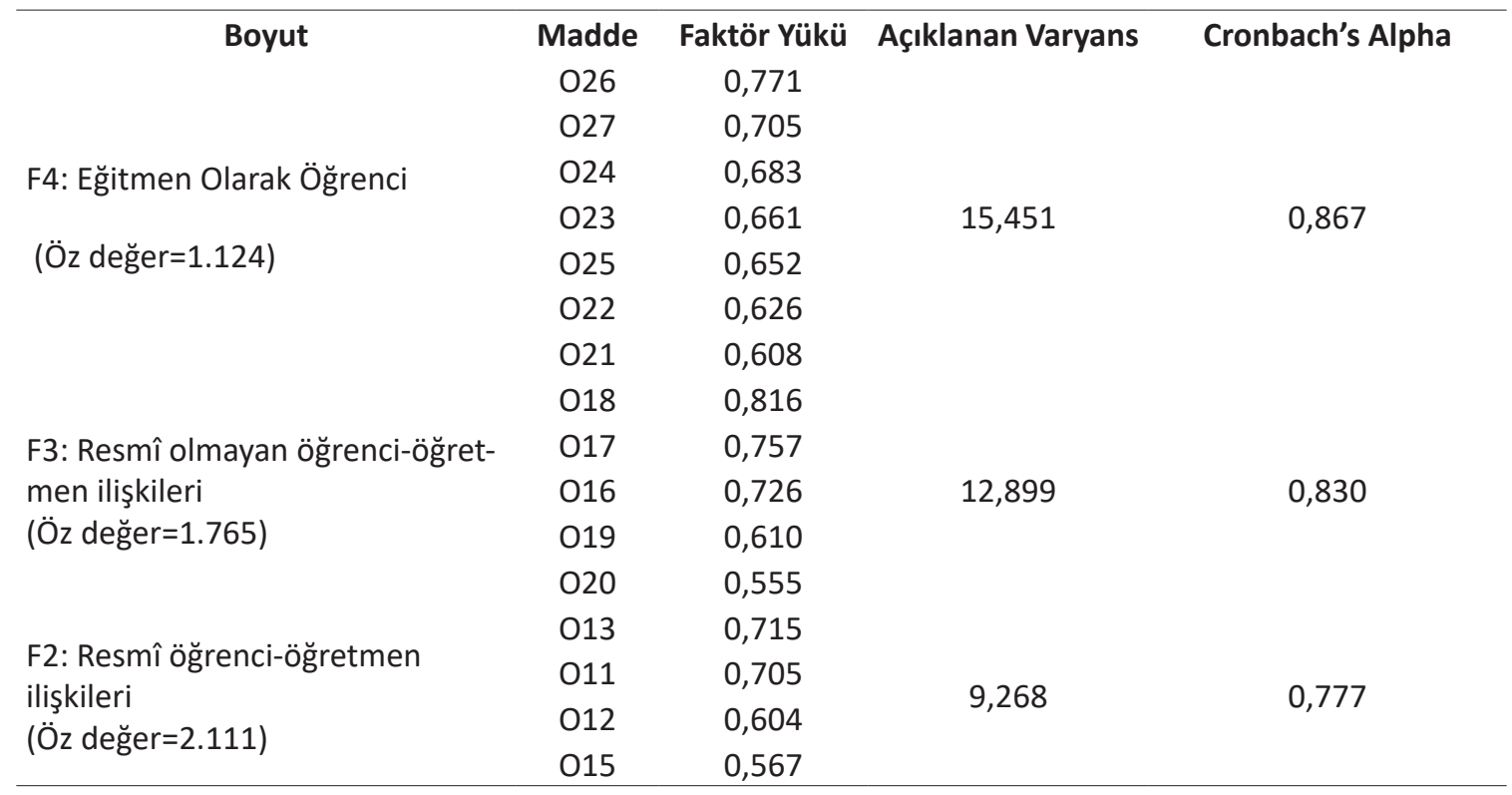

Toplam Varyans \%56.489, Barlett Testi $(p)=0.000<0.05$, Kaiser Meyer Olkin $(K M O)=0.920>0,60$

Açıklayıcı faktör analizi sonuçlarının doğrulayıcı faktör analizi sonuçları ile örtüştüğü saptanmıştr. Tablo 3'te görüldüğü gibi genel öğrenci-öğrenci ilişkileri için 0,887; resmî öğretmen-öğrenci ilişkileri için 0,777; resmî olmayan öğretmen-öğrenci ilişkileri için 0,830; eğitmen olarak öğrenci faktörü için ise 0,867 Cronbach's Alpha değeri tespit edilmiştir.

\section{Sonuç ve Öneriler}

Bu çalışmada Walker ve Beapler (2017) tarafindan geliştirilen Sosyal Çevre ve Öğrenme Ortamı Ölçeği'nin Türkçeye uyarlanması, geçerlik ve güvenirliğinin incelenmesi gerçekleştirilmiştir. Çeviri aşamasında uzman görüşleri doğrultusunda ölçek Türkçeye çevrilmiş ve farklı bölümlerden 310 öğretmen adayı ile uygulamalar gerçekleştirilmiştir. Analizler neticesinde, ölçeğin güvenirliğini ifade eden Cronbach's Alpha değeri 0,931 olarak bulunmuştur. i̇ç tutarlılığı olumsuz etkileyen ve madde toplam korelasyon değeri 0,17 olan 14 numaralı "Bazen öğretmenim ve kendimi sınıfta zıt grupmuşuz gibi hissediyorum" maddesi ölçekten çıkartılmış ve 26 madde, 4 boyuttan oluşan bir ölçek olduğu görülmüştür. Ölçeğin, (1-10. Maddeler) birinci alt boyutu genel öğrenci-öğrenci ilişkileri için 0,887; ikinci alt boyutu (11-15. maddeler[14. madde çıkarıldı]) resmî öğretmen-öğrenci ilişkileri için 0,777; üçüncü alt boyutu (16-20. maddeler) resmî olmayan öğretmen-öğrenci ilişkileri için 0,830; dördüncü alt boyutu (21-27. maddeler) eğitmen olarak öğrenci faktörü için ise 0,867 Cronbach's Alpha değeri tespit edilmiştir.

Ölçek, toplam varyansı \%56.489 oranında açıklamıştı. Ölçek geliştirme ve uyarlama çalışmalarında açıklanan varyans oranı için \%30 ve üzeri ölçüt olarak alındığı (Ural ve Kılıç, 2006) düşünüldüğünde, ölçeğin yapı geçerliğinin sağlandığı görülmektedir 26 madde, 4 alt boyuttan oluşan Sosyal Çevre ve Öğrenme Ortamı Ölçeği'nin geçerli ve güvenilir bir ölçme aracı olarak öğrenme ortamlarında kullanılabileceği söylenebilir. Ölçek uyarlama çalışmaları, eğitim fakültesi öğrencileri ile gerçekleştirilmiştir. Araştırmacılar tarafindan yapılacak farklı çalışmalarda farklı yaş ve örneklem gruplarında ölçeğe ilişkin geçerlik ve güvenirlik çalışmaları yapılabilir. Ayrıca ölçeğin, farklı beceri alanları ile öğrenme ortamının ilişkisini tespit etmede kullanılabileceği düşünülmektedir.

\section{Kaynakça}

Apaydın, Ç. ve Kızılhan, P. (2011). Üniversitelerde sınıf öğrenme çevresinin ikinci mertebeden faktör analizi. Kuram ve Uygulamada Eğitim Yönetimi,17(4), 509-526.

Awang, Z. (2015). SEM made simple: A gentle approach to learning Structural Equation Modelling. Bandar Baru Bangi: MPWS Rich Publication.

Çokluk, Ö., Şekercioğlu, G. ve Büyüköztürk, Ş. (2010). Sosyal bilimler için çok değişkenli istatistik. Ankara: Pegem Yayınları.

Dorman, J. P., Fraser, B., \& McRobbie, C. J. (1997). Relationship between school level-and classroom level environments in secondary schools. Journal of Educational Administration, 35(1), 74-91.

Fisher, D.L. \& Fraser, B.J. (1981). Validity and use of my class inventory. Science Education, 65, 145-156.

Fraser, B.J. (1998). Science learning environments: Assessment, effects and determinants. In B.J. Fraser and K.G. Tobin (Eds.). International Handbook Of Science Education. Dordrecht, The Netherlands: Kluwer. 
Garrison, D. R. (2000). Theoretical challenges for distance education in the 21st century: A shift from structural to transactional issues. International Review of Research in Open and Distance Learning, 1(1).

Hooper, D., Coughlan, J., \& Mullen, M. R. (2008). Structural equation modeling: Guidelines for determining model fit. Electronic Journal of Business Research Methods, 6(1), 53-60.

Kandemir, M., Çakır, O. ve Eşici, H. (2008). Üniversite öğrencilerinin sınıf içinde algıladıkları empatik atmosfer ile benlik saygıları arasındaki etkileşimin sosyal özyeterlikle ilişkisi. 17. Ulusal Eğitim Bilimleri Kongresi, Sakarya Üniversitesi Eğitim Fakültesi.

Karasar, N. (2009). Bilimsel araştırma yöntemi. Ankara: Nobel Yayınları.

Kısakürek, M. A. (1985). Sınıf atmosferinin öğrenci başarısına etkisi eğitim fakülteleri üzerine bir araştırma. Ankara: Ankara Üniversitesi Eğitim Bilimleri Fakültesi Yayınları.

Kline, B. (2005). Principles and practice of structural equation modeling. Newyork: The Guilford Press.

Köse, E. ve Küçükoğlu, A. (2009). Eğitim fakültelerindeki sınıf öğrenme çevresinin bazı değişkenler açısından değerlendirilmesi. Ahi Evran Üniversitesi Eğitim Fakültesi Dergisi, 10(3), 61-73.

Küçüközer, H., Kırtak Ad V. N., Ayverdi, L. ve Eğdir, S. (2012). Yapılandırmacı öğrenme ortamları ölçeğinin Türkçe’ye uyarlanması, ilköğretim Online, 11(3), 671-688.

Moos, R.H. (1979). Evaluating Educational Environments: Procedures, Measures, Findings and Policy Implications, Jossey-Bass, San Francisco, CA.

Higgs, B., \& McCarthy, M. (2005). Active learning-from lecture theatre to field-work. In G. O'Neill, S. Moore, \& B. McMullin (Eds.), Emerging issues in the practice of university learning and teaching, 37-44. Dublin: All Ireland Society for Higher Education.

Rentoul, A.J. \& Fraser, B.J. (1979). Conceptualization of enquiry-based or open classroom learning environments. Journal of Curriculum Studies, 11, 233-245.

Schumacker, R. E. \& Lomax, R. G. (2004). A beginner's guide to structural equation modeling. New Jersey: Taylor \& Francis.

Sümer, N. (2000). Yapısal eşitlik modelleri. Türk Psikoloji Yazıları, 3(6), 49-74.

Şencan, H. (2005). Sosyal ve davranışsal ölçümlerde güvenilirlik ve geçerlilik. Ankara: Seçkin Yayıncılık.

Şimşek Ö. F. (2007). Yapısal eşitlik modellemesine giriş, temel ilkeler ve LiSREL uygulamaları. Ankara: Ekinoks Yayınları.

Tabachnick, B. G. \& Fidel, L. S. (2007). Using multivariate statistics. Pearson Education Inc. Boston.

Taylor, P., Fraser, B. J. \& Fisher, D.L. (1997). Monitoring constructivist classroom learning environments. International Journal of Educational Research, 27, 293-302.

Taylor, P. C., Fraser, B. J. \& White, L. R. (1994). CLES an instrument for monitoring the development of constructivist learning environments. American Educational Research Association, New Orleans.

Terwel, J. (1999). Constructivism and its implications for curriculum theory and practice. Journal of Curriculum Studies, 31(2), 195-199.

Tu, C. H., \& Corry, M. (2002). elearning communities. The Quarterly Review of Distance Education, 3(2), $207-218$.

Ural, A. ve Kılıç, I. (2006). Bilimsel araştırma süreci ve SPSS ile veri analizi (Genişletilmiş 2. Baskı). Ankara: Detay Yayıncılık.

Walberg, H. J., \& Anderson, G. J. (1968). Classroom climate and individual learning. Journal of Educational Psychology, 59(6), 414-419.

Walker, J. D. \& Baepler, P. (2017). Measuring social relations in new classroom spaces: Development and validation of the social context and learning environments (scale) survey. Journal of Learning Spaces, 6/3, 34-41.

Waltz, C. F., Strcikland, O. L. \& Lenz, E. R. (2010). Measurement in nursing and health research. New York: Springer Publishing Company.

Wang. J. \& Wang, X. (2012). Structural equation modeling: applications using mplus: methods and applications. West Susex: John Wiley \& Sons.

Vygotsky, L. S. (1978). Mind in society: The development of higher psychological processes. Cambridge, MA: Harvard University Press.

Vygotsky, L. S. (1986). Thought and language. Cambridge, MA: The MIT Press. 


\section{Sosyal Çevre ve Öğrenme Ortamı Ölçeği}

1. Sınıf arkadaşlarımdan bir şeyler öğrendim.

2. Yakınımda oturan öğrenciler, ders materyallerini öğrenme konusunda birbirlerine yardım ederler ve birbirlerine güvenirler.

3. Genel olarak, sınıfta yakınımda oturan kişiler, sınıf ödevleri, sorular vb. gibi sınıf çalışmalarında birlikte iyi çalışırlar.

4. Sınıfta yakınımda oturan öğrenciler hakkında bir şeyler bilirim (Kendileriyle ilgili bilgileri benimle paylaşırlar).

5. Sınıf arkadaşlarımdan yardım isterken kendimi rahat hissederim.

6. Sınıfta yanımda oturan arkadaşlarımla tanışırım.

7. Ders sırasında, bazı arkadaşlarımla ders materyallerini tartışma şansım olur.

8. Yakınımda oturan öğrenciler benim görüşlerime saygı duyarlar.

9. Sınıf arkadaşlarım yararlı bir kaynak belirtti.

10. Sınıf arkadaşlarım bir kavramı bana açıkladı.

11. Dersteki testler ve ödevleri kapsayan materyal, sınıfta veya çevrimiçi olarak sunuldu ve tartş̧ıldı.

12. Öğretmenim dersi keyifli hale getirir.

13. Öğretmenim derse ait test ve ödevleri iyi yapmamı ister.

14. Öğretmenim, öğrencilerden soru ve yorum gelmesi konusunda onları cesaretlendirir.

15. Öğretmenim ismimi bilir.

16. Öğretmenim benimle ilgili gibi görünür.

17. Öğretmenim bana sıcak davranır.

18. Ben öğretmenime sıcak davranırım.

19. Öğretmenimle dersten önce, ders sırasında veya ders sonrasında gayri resmi olarak konuşurum.

20. Fikirlerimi belirli terimlerle açıklayabilirim.

21. Yakınımda oturan arkadaşlarım bu ders döneminde benden bir şeyler öğrendiler.

22. Öğrendiğim yeni kavramları derste arkadaşlarıma açık bir şekilde anlatabilirim.

23. Sınıf arkadaşlarımı, fikirlerimin bu sınıfta karşılaşthğımız problemlerle niçin alakalı olduğu konusunda ikna edebilirim

24. Terminolojiyi sınıfta doğru biçimde kullanabilirim.

25. Düşüncelerimi sınıfta arkadaşlarıma baştan sona açıklayabilirim.

26. Sınıf arkadaşlarımın öğrenmelerine yardımcı olabilirim.

\begin{tabular}{|c|c|c|c|c|}
\hline 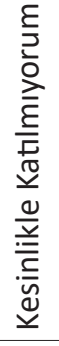 & 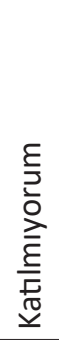 & 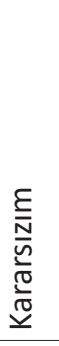 & 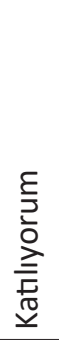 & 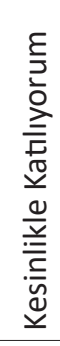 \\
\hline & & & & \\
\hline & & & & \\
\hline & & & & \\
\hline & & & & \\
\hline & & & & \\
\hline & & & & \\
\hline & & & & \\
\hline & & & & \\
\hline & & & & \\
\hline & & & & \\
\hline & & & & \\
\hline & & & & \\
\hline & & & & \\
\hline & & & & \\
\hline & & & & \\
\hline & & & & \\
\hline & & & & \\
\hline & & & & \\
\hline & & & & \\
\hline & & & & \\
\hline & & & & \\
\hline & & & & \\
\hline & & & & \\
\hline & & & & \\
\hline & & & & \\
\hline & & & & \\
\hline
\end{tabular}

